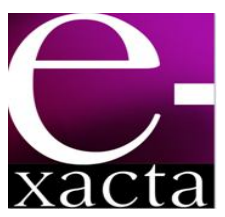

ISSN: 1984-3151

\section{ESTUDO DA PREPARAÇÃO E DA MORFOLOGIA DE SUPERFÍCIE DE ALUMINA NANOPOROSA AUTO-ORGANIZADA}

\author{
STUDY OF PREPARATION AND SURFACE MORPHOLOGY OF \\ SELF-ORDERED NANOPOROUS ALUMINA
}

\author{
Elisa Marchezini Rodrigues'; Ronald Arreguy Silva²; Maximiliano Delany Martins ${ }^{3}$ \\ 1 Mestranda em Ciência e Tecnologia das Radiações, \\ Minerais e Materiais. Centro de Desenvolvimento da \\ Tecnologia Nuclear - CDTN/CNEN. Belo Horizonte, MG. \\ elisamarch@gmail.com. \\ 2 Doutor em Química. UFMG, 2008. Professor Assistente, \\ Centro Universitário de Belo Horizonte - UniBH. Belo \\ Horizonte, MG. arregsilva@yahoo.com.br. \\ 3 Doutor em Física. UFMG, 2001. Pesquisador Titular, Centro \\ de Desenvolvimento da Tecnologia Nuclear - CDTN/CNEN. \\ Belo Horizonte, MG. mdm@cdtn.br.
}

Recebido em: 13/09/2013 - Aprovado em: 22/11/2013 - Disponibilizado em: 30/11/2013

RESUMO: A alumina nanoporosa é um material que apresenta nanocanais auto-ordenados espontaneamente em formato hexagonal. Produzida a partir da anodização do alumínio metálico, vem sendo usada como molde para produção de materiais em escala nanométrica. Este trabalho teve como objetivo o estudo da preparação e a caracterização morfológica da alumina na noporosa auto-organizada. A alumina nanoporosa foi preparada seguindo-se a metodologia proposta por Masuda e Fukuda (1995), um método de dois passos de anodização que consiste em anodizar a amostra de alumínio, remover a camada de óxido de alumínio (alumina) formada e, em seguida, repetir o processo de anodização, sob as mesmas condições da primeira. Este procedimento resulta em alumina com poros de dimensão na faixa de dezenas de nanômetros, com estreita distribuição de tamanhos $e$ com alto grau de ordenação.

PalAVRAS-CHAVE: Alumina nanoporosa. Anodização. Alumínio. Nanotecnologia.

ABSTRACT: Nanoporous alumina is a typical material that exhibits self-ordered nanochannels spontaneously organized in hexagonal shape. Produced by anodizing of metallic aluminum, it has been used as a template for production of materials at the nanoscale. This work aimed to study the preparation of nanoporous alumina by anodic anodizing of metallic aluminum substrates. The nanoporous alumina was prepared following the methodology proposed by Masuda and Fukuda (1995), a two-step method consisting of anodizing the aluminum sample in the potentiostatic mode, removing the layer of aluminum oxide (alumina) formed and then repeat the anodization process under the same conditions as the first anodization. This method produces nanoporous alumina with narrow pore diameter distribution and well-ordered structure.

KEYWORDS: Nanoporous alumina. Anodization. Aluminum. Nanotechnology.

\section{INTRODUÇÃO}

O termo Nanotecnologia foi criado em 1974 por Norio Taniguchi, pesquisador da universidade de Tóquio, para descrever a habilidade de se manipular os materiais em escala nanométrica $\left(10^{-9} \mathrm{~m}\right)$. De um modo mais prático, a nanotecnologia lida com estruturas com pelo menos uma dimensão na faixa de 1 a 100 nanômetros (ZARBIN, 2007). A habilidade de manipular a matéria em escala atômica e molecular associada aos diferentes fenômenos observados nos materiais de dimensionalidade reduzida (chamados 
materiais nanoestruturados ou nanomateriais) como, por exemplo, aqueles causados pelo confinamento de tamanho e pela redução da razão volume/área superficial têm despertado grande interesse devido às potenciais aplicações, sendo que algumas destas já mostram os seus efeitos na tecnologia e na vida cotidiana. Como exemplos desses novos materiais nanoestruturados podemos citar os nanotubos de carbono, as estruturas auto-organizadas como os pontos quânticos em heteroestruturas semicondutoras; as válvulas de spin usadas em sensores de campo e cabeças de leitura de discos rígidos de alta densidade; as moléculas baseadas na estrutura do DNA; e os dispositivos moleculares.

Nos últimos anos, materiais que apresentam canais nanométricos uniformes têm estimulado consideravelmente 0 interesse dos pesquisadores devido à sua potencial aplicação como molde para a fabricação de novos materiais nanoestruturados (MASUDA et al., 1997). Um exemplo de material nanoporoso é a alumina (óxido de alumínio $-\mathrm{Al}_{2} \mathrm{O}_{3}$ ) porosa auto-ordenada. Produzida a partir da anodização do alumínio metálico, a alumina nanoporosa vem sendo empregada como molde para a produção de materiais em escala nanométrica com estrutura regular e de forma reprodutível (ALMEIDA, 2009).

Este trabalho teve como objetivo estudar o processo de preparação da alumina nanoporosa via oxidação anódica (anodização) de alumínio. Além disso, investigou-se o efeito do crescimento de grão via tratamento térmico do substrato de alumínio na organização de longo alcance da estrutura da alumina nanoporosa.

\section{REVISÃo BIBLIOGRÁFICA}

A alumina nanoporosa é um típico material que apresenta nanocanais auto-ordenados, organizados espontaneamente em formato hexagonal. Ela apresenta em sua estrutura uma matriz de células colunares, cada uma contendo um poro central, onde tamanho e intervalo podem ser controlados alterandose as condições de preparação (MASUDA et al., 1997).

Pode-se entender a formação da estrutura porosa como um equilíbrio entre a formação-dissolução do óxido, no qual o favorecimento da dissolução de algumas regiões fornece a geometria hexagonal ordenada obtida em determinadas condições (CROUSE et al., 2000). Nas reações eletroquímicas que ocorrem durante o processo de anodização, que acontecem na base dos poros, a alumina é formada na interface alumina/alumínio e dissolvida na interface solução/alumina, sendo o equilíbrio entre estas duas reações um fator importante para crescimento dos poros na alumina (RAMOS, 2010).

Durante o processo de anodização, a composição da solução está sempre mudando devido ao aumento da concentração dos íons $\mathrm{H}^{+}$, que ocorre pelo consumo de oxigênio na formação da alumina, e a sua dissolução causa um acúmulo de íons $\mathrm{Al}^{+}$na solução. Esta concentração de íons na solução pode diminuir a densidade da corrente (RAMOS, 2010).

A análise da curva de densidade de corrente versus tempo, obtida durante o processo de anodização no modo potenciostático, como a representada na Figura 1, revela detalhes sobre o processo de oxidação. Após a tensão ser aplicada, uma elevada corrente é imediatamente observada como resultado da formação de íons $\mathrm{Al}^{+3}$ em decorrência da oxidação do alumínio metálico. A seguir, a corrente cai bruscamente em consequência do aumento da resistência no eletrodo, resultado do rápido crescimento de uma camada de $\mathrm{Al}_{2} \mathrm{O}_{3}$ não poroso e isolante. O óxido de alumínio é formado devido à interação dos íons $\mathrm{O}^{-2}$, provenientes do eletrólito, com os íons $\mathrm{Al}^{+3}$, gerados na oxidação do alumínio 
metálico. Durante o processo de anodização, a camada de óxido continua a crescer na interface metal-óxido devido à migração das espécies $\mathrm{O}^{-2} \mathrm{da}$ interface óxido-solução para a interface metal-óxido, sob a ação do campo elétrico. O aquecimento local surge como resultado do aumento da resistência elétrica do material, promovendo a dissolução em regiões preferenciais da barreira óxida formada, o que resulta em um pequeno aumento no valor da densidade de corrente em função da liberação de espécies carregadas para o eletrólito. Finalmente, a densidade de corrente atinge um valor que permanece constante até o final da anodização, indicando que o equilíbrio foi atingido: a taxa de dissolução local do óxido se igualou à taxa de formação do óxido de barreira na base dos poros (CHEN et al., 2007).

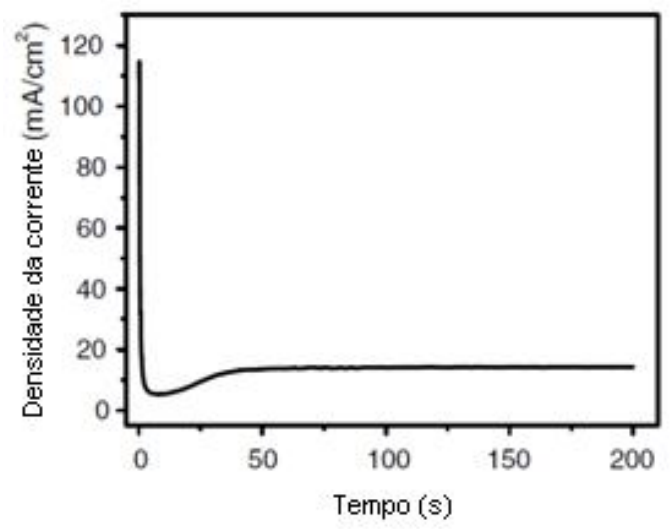

Figura 1 - Curva típica de densidade de corrente $x$ tempo durante o processo de anodização de alumínio. Fonte - CHEN et al., 2007

Masuda e Fukuda (1995) propuseram um método de dois passos de anodização que consiste na anodização, no modo potenciostático, do substrato de alumínio, seguida da remoção da camada de alumina formada e, finalmente, uma segunda etapa de anodização, sob as mesmas condições da primeira. Em comparação com o método convencional de uma etapa, este procedimento produz alumina nanoporosa com elevado grau de ordenação espacial e pequena dispersão do diâmetro médio dos nanoporos.

Um aspecto importante a ser analisado é o diâmetro médio dos poros formados na alumina, uma vez que as condições de preparação são determinantes no tamanho dos poros. Na literatura é possível encontrar valores de referência para esse parâmetro na faixa de 50 a $70 \mathrm{~nm}$, para amostras preparadas em condições semelhantes às deste trabalho (MASUDA et al., 1997; MASUDA; FUKUDA, 1995; CROUSE et al. 2000).

\section{Metodologia}

Para obtenção da alumina nanoporosa, amostras de alumínio ultrapuro, na forma de discos com diâmetro de $10 \mathrm{~mm}$ e espessura $2 \mathrm{~mm}$, foram lixadas e polidas mecanicamente, utilizando-se lixas com granulometria de 1200 e 2000 e feltros com pasta de diamante de 1 e $3 \mu \mathrm{m}$. Logo após, fez-se o tratamento térmico das amostras a $500{ }^{\circ} \mathrm{C}$, em atmosfera de nitrogênio ultrapuro. Em seguida, cada amostra passou por duas etapas de anodização, de 2 horas de duração cada uma. Para isso, utilizou-se uma solução de ácido oxálico $0,3 \mathrm{~mol} / \mathrm{L}$, à temperatura de $5{ }^{\circ} \mathrm{C}$ e tensão de $40 \mathrm{~V}$. Entre a primeira e a segunda etapa de anodização, removeu-se a primeira camada de óxido formada, para que desse lugar à outra mais ordenada formada durante a segunda anodização. No procedimento de remoção da primeira camada de óxido, utilizou-se solução de ácido crômico 0,3 mol/L e ácido fosfórico $0,4 \mathrm{~mol} / \mathrm{L}$, em um tempo de 2 a $4 \mathrm{~min}$, à temperatura de $60 \stackrel{\circ}{\circ}$. Finalmente, fez-se a revelação dos poros usando-se uma solução de ácido fosfórico $5 \% \mathrm{~m} / \mathrm{v}$, a $30 \stackrel{\circ}{\circ}$. As amostras preparadas segundo este roteiro receberam a nomenclatura de amostras da "Série A".

As anodizações foram feitas utilizando-se uma célula eletroquímica construída no Laboratório de Nanoscopia/LabNano do CDTN. Esta célula consiste 
em uma câmara cilíndrica construída em teflon, onde é colocada a solução, com um suporte na parte superior para termômetro e contra-eletrodo (anodo) de platina. Ao fundo, a câmara apresenta um pequeno orifício que permite que a amostra fique em contato direto com a solução. Na parte inferior da célula, servindo de suporte de fixação para a amostra, há uma placa de cobre que permite o contato térmico da amostra com uma placa de resfriamento (tipo Peltier). O contato elétrico da amostra (catodo) também é feito através desta placa metálica. Um agitador mecânico mantém a solução em constante agitação durante o processo de anodização. A Figura 2 mostra uma foto do arranjo experimental para a preparação de amostras por anodização no LabNano (agitador mecânico, célula eletroquímica e placa de resfriamento).

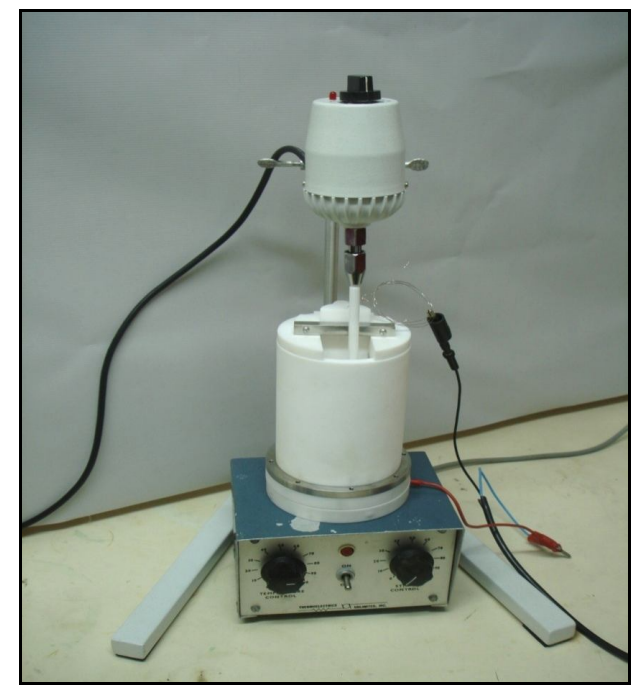

Figura 2 - Arranjo experimental para anodização, montado no LabNano/CDTN.

Fonte - ALMEIDA, 2009

Este arranjo experimental é equipado com um sistema eletrônico de monitoramento que permite armazenar os parâmetros característicos do processo (tensão e corrente elétricas aplicadas na célula eletroquímica, temperatura da solução) durante a anodização da amostra. A análise da curva de densidade de corrente, após o procedimento de anodização, permite avaliar o grau de sucesso do processo de anodização e formação dos nanoporos.

Como exemplo, a Figura 3 mostra a curva de densidade de corrente para uma situação em que o processo de anodização foi interrompido de forma espontânea antes do final do procedimento, o que sugere que $o$ processo de formação da alumina nanoporosa não se completou.

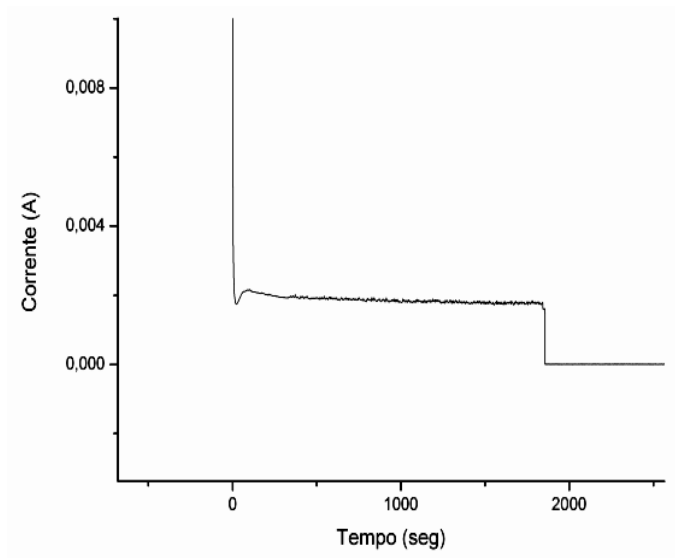

Figura 3 - Curva de densidade de corrente $\mathrm{x}$ tempo durante o processo de anodização de alumínio, mostrando a interrupção espontânea do processo.

Após a preparação, a morfologia da alumina nanoporosa formada na superfície das amostras foi analisada por microscopia eletrônica de varredura de alta resolução (MEV). As medidas de MEV foram realizadas no CDTN e no Centro de Microscopia da Universidade Federal de Minas Gerais (UFMG).

Para correlacionar a organização de longo alcance na estrutura da alumina nanoporosa com o tamanho de grão do alumínio, repetiu-se o mesmo procedimento de anodização em amostras sem tratamento térmico (amostras da "Série B"). Também foram feitas imagens destas amostras no MEV do Centro de Microscopia da UFMG. 
De modo a caracterizar a influência do tratamento térmico no tamanho dos grãos nas amostras de alumínio, duas amostras ("Série C") apenas polidas mecanicamente, uma com tratamento térmico e outra sem, foram atacadas com uma solução de $100 \mathrm{~mL}$ de $\mathrm{H}_{2} \mathrm{O}$ destilada, $7,5 \mathrm{~mL}$ de $\mathrm{HF}, 4,2 \mathrm{~mL}$ de $\mathrm{HCl}$ e $4,2 \mathrm{~mL}$ de $\mathrm{HNO}_{3}$. O objetivo deste ataque químico é revelar a estrutura de grãos das amostras, como mostrado na figura 8.

Finalmente, calculou-se o diâmetro médio dos poros formados nas Séries A e B. Tal procedimento foi realizado com o auxílio do pacote de processamento de imagens ImageJ (http://rsb.info.nih.gov/ij). Este programa fornece os diâmetros - maior e menor - da elipse que melhor se aproxima de cada um dos poros da amostra. Com a média desses valores obtém-se um valor aproximado de diâmetro para uma esfera. $\mathrm{O}$ diâmetro médio da amostra é dado pela média global dos diâmetros das esferas.

\section{Resultados e Discussão}

A seguir, estão detalhados os resultados obtidos para cada amostra analisada.

\subsection{Amostra A2}

A Figura 4 mostra imagens de MEV típicas para a mesma região da superfície da amostra $\mathrm{A} 2$, com diferentes aumentos (20.000X e 50.000X).

A temperatura durante o processo de anodização foi de $10 \stackrel{\circ}{ } \mathrm{C}$. Verifica-se que houve a formação de nanoporos, com uma dispersão muito pequena de tamanhos, mas sem apresentar alto grau de ordenamento. A análise quantitativa da imagem revelou que o diâmetro médio dos poros para esta amostra é de $(47 \pm 9) \mathrm{nm}$.
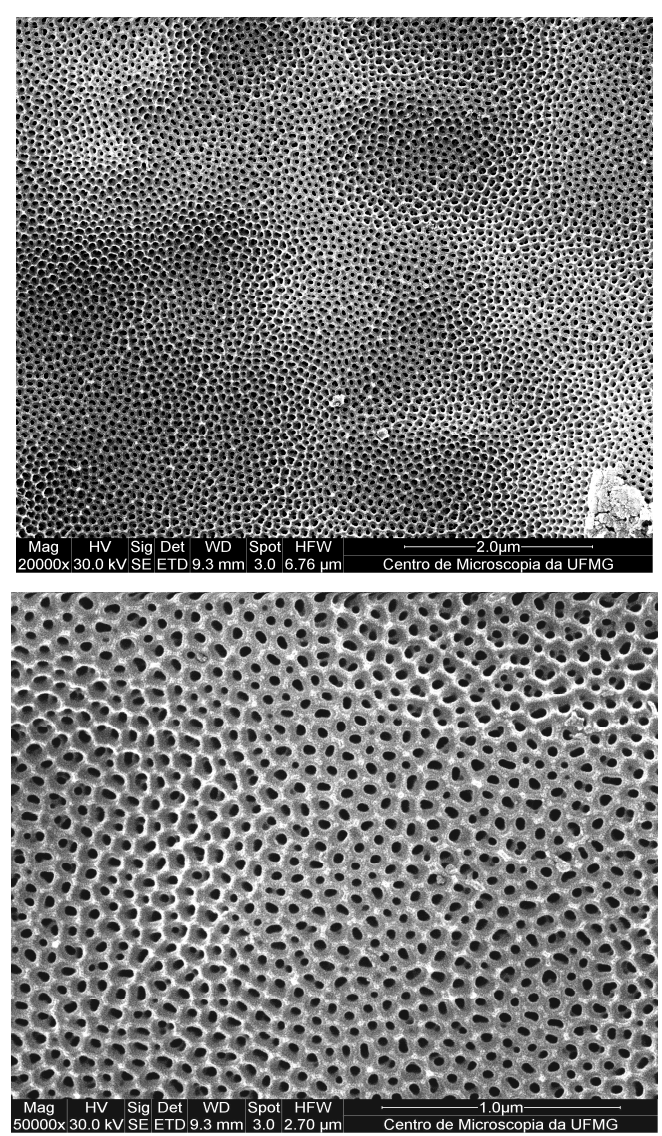

Figura 4 - Imagens de MEV da amostra A2 (aumento da imagem superior: $20.000 \mathrm{X}$; inferior: $50.000 \mathrm{X}$ ).

\subsection{Amostra A16}

A Figura 5 apresenta a caracterização da superfície da amostra A16 por MEV (aumentos de 100.000X e $300.000 X)$.

A temperatura durante 0 processo de anodização desta amostra foi de $5^{\circ} \mathrm{C}$.

Observa-se pela figura que os poros formados nesta amostra estão um pouco mais desordenados que na amostra A2. O valor encontrado para o diâmetro médio nesta amostra foi de $(43 \pm 7) \mathrm{nm}$. 

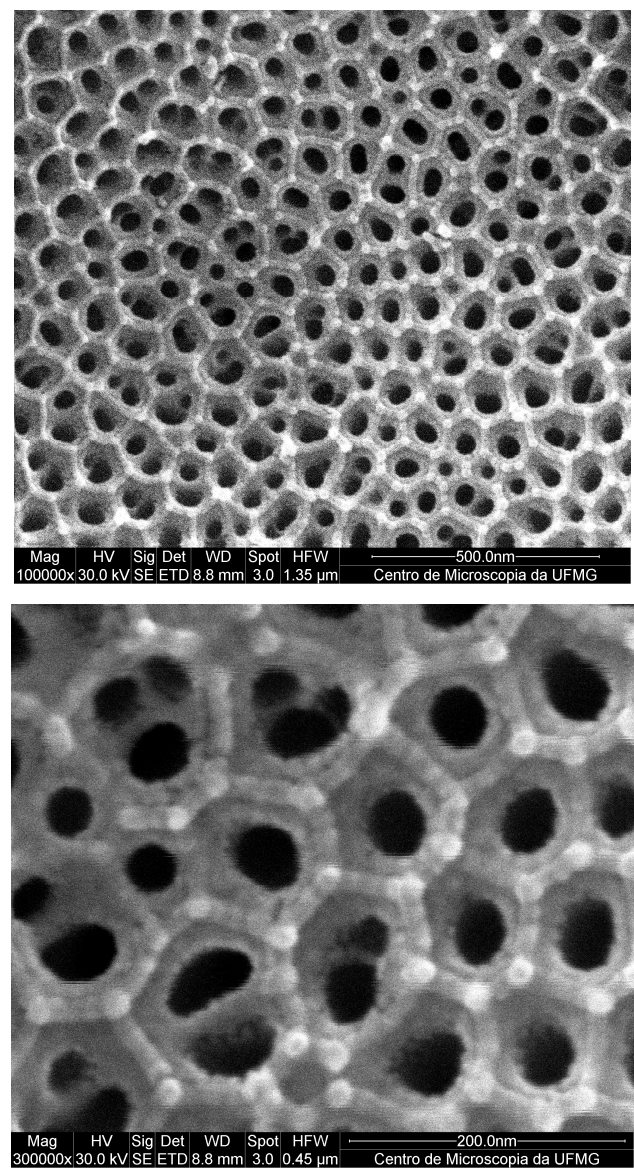

Figura 5 - Imagens de MEV da amostra A16 (aumento da imagem superior: $100.000 \mathrm{X}$; inferior: $300.000 \mathrm{X}$ ).

\subsection{Amostra B1}

A Figura 6 mostra imagens de MEV típicas para a mesma região da superfície da amostra B1, com diferentes aumentos (100.000X e 300.000X).

Estas imagens mostram que houve uma maior ordenação dos poros desta amostra em comparação com as amostras A. Os poros dessa amostra apresentaram diâmetro médio de $(57 \pm 9) \mathrm{nm}$.
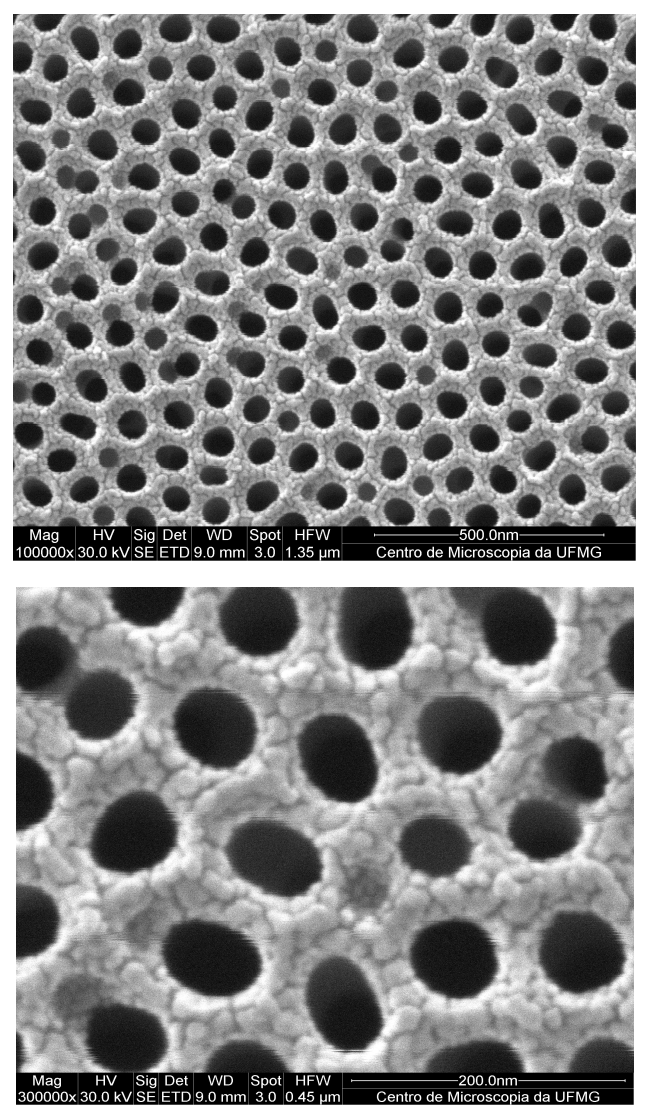

Figura 6 - Imagens de MEV da amostra B1 (aumento da imagem superior: $100.000 \mathrm{X}$; inferior: $300.000 \mathrm{X}$ ).

\subsection{AmostRA B3}

A Figura 7 mostra imagens de MEV típicas para a mesma região da superfície da amostra B3, com diferentes aumentos (100.000X e 300.000X).

Observa-se que os poros formados nesta amostra estão bastante desordenados. É possível ver um certo desnível na superfície, o que pode ter sido causado na etapa de polimento mecânico da amostra, prejudicando a formação ordenada dos poros. O valor encontrado do diâmetro médio para essa amostra foi de $(45 \pm 8) \mathrm{nm}$. 

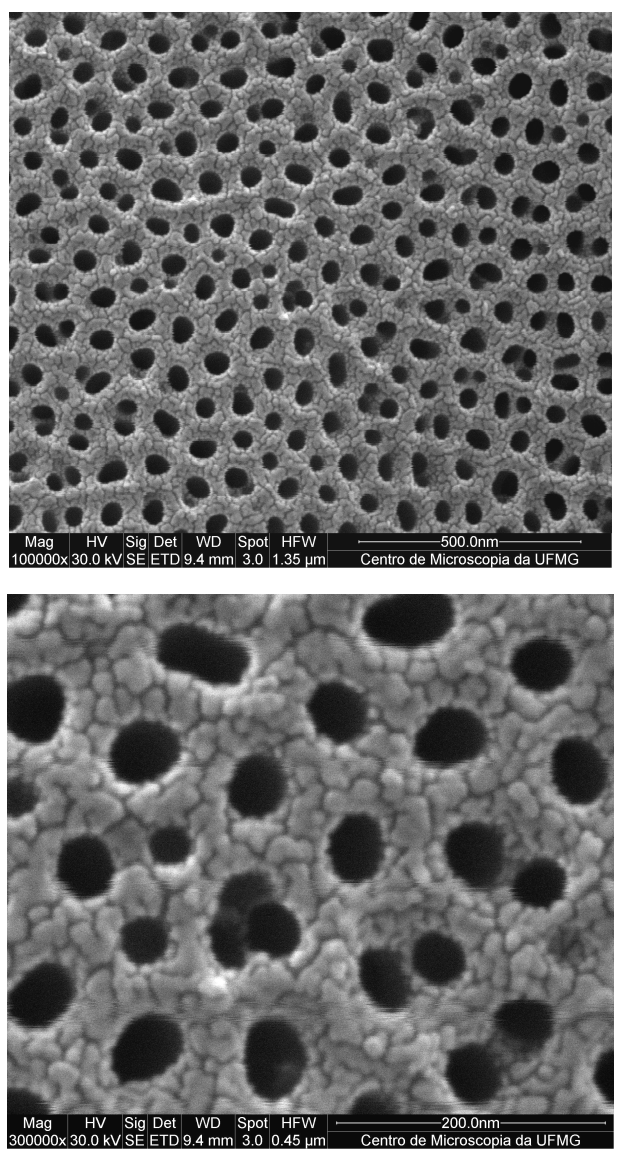

Figura 7 - Imagens de MEV da amostra B3 (aumento da imagem superior: 100.000X; inferior: 300.000X).

Os valores de diâmetro médio dos nanoporos para cada uma das amostras das séries $A$ e $B$ são apresentados na Tabela 1.

Tabela 1

Diâmetros médios dos poros das amostras $A$ e B

\begin{tabular}{|c|c|c|c|c|}
\hline Amostra & A2 & A16 & B1 & B3 \\
\hline $\begin{array}{c}\text { Diâmetro } \\
\text { médio } \\
(\mathrm{nm})\end{array}$ & $47 \pm 9$ & $43 \pm 7$ & $57 \pm 9$ & $45 \pm 8$ \\
\hline
\end{tabular}

Comparando-se os valores encontrados dos diâmetros médios das amostras analisadas com os valores de referência encontrados na literatura, observa-se que, se considerado o erro experimental de cada medida, os valores estão próximos à faixa desejada.

Verificou-se que as amostras não apresentaram reprodutibilidade, ou seja, amostras submetidas às mesmas condições não apresentaram estruturas semelhantes entre si. Isso pode ter ocorrido por interferência de algum contaminante não identificado que possa alterar a formação dos poros. Uma outra explicação seria a diferença na concentração de íons na solução entre uma anodização e outra, uma vez que as amostras foram feitas em datas diferentes. Segundo Ramos esta diferença pode alterar a densidade da corrente, um dos parâmetros que definem a morfologia dos nanoporos. Apesar disso observou-se a formação dos nanoporos de alumina em todas as amostras aqui analisadas.

\subsection{Amostras C}

A Figura 8 apresenta imagens diretas das amostras da Série C. Através desta imagem observa-se claramente que o tratamento térmico provoca um considerável aumento no tamanho de grão do alumínio. Contudo, esta diferença só é perceptível nestas amostras (sem as etapas de anodização), ou seja, não é possível observar diferença, através deste trabalho, entre as amostras A e B com relação ao tamanho de grão.

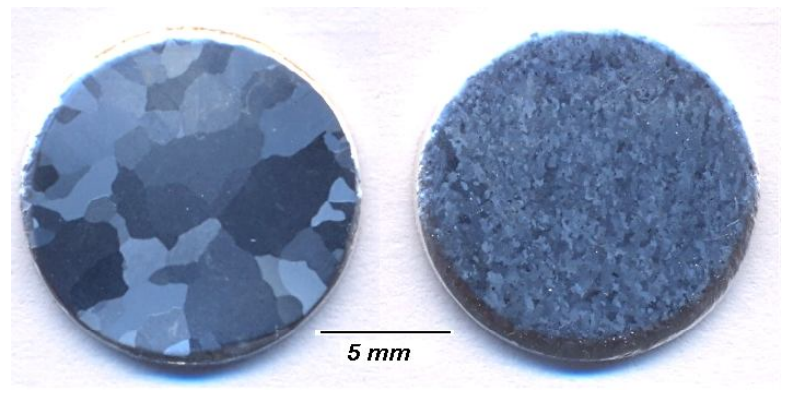

Figura 8 - Imagem direta das amostras da Série C, após 0 ataque químico para revelação dos grãos.

e-xacta, Belo Horizonte, v. 6, n. 2, p. 61-68. (2013). Editora UniBH. Disponível em: www.unibh.br/revistas/exacta 
Provavelmente, seria necessária uma imagem com maior área de abrangência, porém com um grande aumento para que fosse localizado o contorno de um grão e se observasse a diferença de orientação dos nanoporos.

\section{CONCLUSÕES}

Quanto à preparação da alumina, apesar de as amostras não apresentarem reprodutibilidade, os resultados obtidos foram satisfatórios, pois a alumina nanoporosa foi formada em todos os casos analisados.

Os diâmetros médios dos poros nas amostras analisadas estão próximos da faixa desejada, se for considerado o erro experimental de cada medida.

Observando-se os resultados obtidos, alguns ajustes ainda devem ser feitos para se obter melhores resultados, especialmente maior regularidade da organização na estrutura de nanoporos da alumina. O procedimento de anodização envolve uma grande quantidade de parâmetros (solução, temperatura, tensão de anodização, etc) e que precisam ser ajustados para que se obtenha melhores resultados.

Através da análise feita nas amostras C, foi comprovado que o tratamento térmico aumenta o tamanho de grão do alumínio. Porém, este aumento não pôde ser observado comparando-se as amostras de alumina nanoporosa (amostras das séries A e B). Como mostrado na figura 8 , os grãos apresentam dimensão na faixa de milímetros, o que dificulta a investigação do ordenamento de longo alcance na estrutura de nanoporosa da alumina por microscopia eletrônica convencional.

\section{AGRADECIMENTOS}

Os autores agradecem o apoio das agências CAPES, CNPq e FAPEMIG.

\section{REFERÊNCIAS}

ALMEIDA, J. A. Preparo e Caracterização de Estruturas Nanoporosas em Alumínio por Oxidação Anódica. 2009. 88 f. Dissertação (Mestrado em Ciência e Tecnologia das Radiações, Minerais e Materiais), Centro de Desenvolvimento da Tecnologia Nuclear, Belo Horizonte, Minas Gerais. 2009.

CHEN, W. et al. An environment-friendly electrochemical detachment method for porous anodic alumina. Journal of Eletroanalytical Chemistry, v. 600, p. 257-264, 2007.

CROUSE, D. et al. Self-ordered pore structure of anodized aluminum on silicon and pattern transfer. Applied Physics Letters. v. 76, p. 49-51, 2000.
MASUDA, H. e FUKUDA, K. Ordered Metal Nanohole Arrays Made by aTwo-Step Replication of Honeycomb Structures of Anodic Alumina. Science, v. 268, p. 1466-1468, 1995.

MASUDA, $\mathrm{H}$. et al. Highly ordered nanochannel-array architecture in anodic alumina. Applied Physics Letters. v. 71, p. 2770-2772, 1997.

RAMOS, A. K. Produção de Moldes Nanoporos de Alumina. 2010. 48 f. Trabalho de conclusão de curso. (Graduação em Engenharia de Materiais). Universidade Federal de Santa Catarina. Florianópolis.

ZARBIN A. J. G. Química de (nano)materiais. Química Nova. v. 30, p 1469-1479, 2007. 